\title{
Entrevista com aUtora moçAmbicana Emmy XYX
}

laná Souza ${ }^{1}$

Stela Saes ${ }^{2}$

\author{
DOI: 10.11606/issn.1981-7169.crioula.2017.141365
}

entrevista com a escritora moçambicana Manuela
Xavier aconteceu em uma das salas da AEMO (Assono dia 29/06/2016, durante o período em que a pesquisadora laná Souza Pereira lá esteve para pesquisa de campo do seu doutoramento em Psicologia 4 , com recursos da Bolsa Auxílio Mobilidade Santander (Edital PRPG 01/2016). Nela, a escritora fala sobre maternidade, feminismos, literatura e sobre Moçambique. Conhecida pelo pseudônimo de Emmy Xyx, a

1 Psicóloga, mestra em Literatura (FFLCH/USP) e Doutoranda em Psicologia (IP/USP). 2 Professora de Português, Mestra em Literatura (FFLCH/USP) e Doutoranda em Estudos Comparados de Literaturas de Língua Portuguesa (FFLCH/USP)

3 Associação criada em 31 de agosto de 1982, a AEMO é um importante espaço de resistência e fomento à literatura moçambicana. Entendendo a produção literária como um importante ato político e compreendendo o significativo papel social do acesso à literatura, desde sua criação, incentiva o debate, estimula a produção cultural e promove publicações, tendo lançado livros de importantes nomes da literatura moçambicana, como Luís Bernardo Honwana, Marcelino dos Santos, Sérgio Vieira, Noêmia de Sousa, José Craveirinha, dentre outros. Continua atuante na cena cultural moçambicana, incentivando e auxiliando a produção de novos escritores como Emmy Xyx.

4 Sendo a entrevista realizada no âmbito de uma pesquisa em Psicologia Social, é importante ressaltar que o diálogo se realiza de maneira a valorizar a aproximação e o encontro entre entrevistadora e entrevistada. Dessa forma, seguindo as premissas e o método desenvolvido por Ecléa Bosi e utilizado como base para a investigação na área, a entrevista desenvolve-se a partir de um vínculo de confiança e até de amizade que justificam a abordagem mais pessoal e a expressão dos interesses e da vida da escritora. Nesse contexto, é importante ressaltar que a entrevista se elabora como uma conversa, uma troca em que o entrevistado apresenta-se como um parceiro na interpretação e na interrogação do mundo (Gonçalves Filho, J. M. (2003). Problemas de método em psicologia social: algumas notas sobre a humilhação política e o pesquisador participante. In A. M. Bock (Org.), Psicologia e compromisso social (pp. 193-239). São Paulo, SP: Cortez). 
escritora Manuela Xavier nasceu em 1958 no distrito de Angónia, dentro da província de Tete, onde, segundo ela, "se registram as temperaturas mais altas e mais baixas" do país. Após atuar no jornalismo, como colunista dos jornais Embondeiro e Zambebe, Manuela passou a se dedicar à literatura, tendo já publicado as obras Espelho (prosa, 2011), Contar ser gregos (poesia, 2012), de Sol acções a Sol unções (poesia, 2013), Escritas na mão do mar à ria (poesia, 2015) e Cada ver em vez de viver (poesia, 2016). Em entrevista à Revista Crioula, Manuela Xavier relembra seu período escolar, sua fase de colunista e analisa a figura da mulher negra na literatura e na sociedade moçambicana contemporânea. Confira a seguir os principais trechos da conversa com a escritora.

Crioula: Manuela, se a gente fosse considerar só hoje, que é nossa entrevista, nessas poucas horas que nós temos, tudo que a memória trouxer sobre sua infância, juventude, maturidade, literatura, Moçambique e a mulher negra, por qual lembrança mais antiga poderíamos começar?

Emmy Xyx: Após 58 anos não é pouco, não é?! Devia ter aí uns dois anos...recordo-me de ver bois a passar por uma estrada e as pessoas eram muito grandes para mim. Via a minha mãe muito alta e as que estavam a me dar as mãos por aí. Outra também mais antiga me recordo que hão de ter me deixado a dormir dentro de casa, e tinha uma outra pessoa, acho que era uma visita, já não me lembro quem era. Eu despertei e vi que estava sozinha no quarto, e comecei a chorar e a gritar. E lembro minha mãe ter dito a uma de minhas irmãs 
para ir ver porque certamente eu já tinha acordado. Estas são as minhas lembranças mais antigas.

Crioula: Eu queria saber agora de que fatos lembrados e guardados na memória você tem sobre sua condição de muIher. E sua condição de mulher negra. Eu sei que aqui em Moçambique funciona um pouco diferente do Brasil, mas se você pudesse falar um pouco sobre isso, sobre que lembranças mais antigas que você tem dessa sua condição de mulher, de mulher negra.

Emmy Xyx: Dito assim, condição da mulher, é um fato que tenha sido marcado porque eu sinto que vivi pelo fato de ser mulher? Mas é uma situação assim discriminatória?

\section{Crioula: O que você escolher}

Emmy Xyx: Dito assim não tenho lembranças.

Crioula: Você tem lembrança de episódios discriminatórios? Enquanto mulher, enquanto negra... Você viveu essas experiências? Emmy Xyx: Eu vivi algumas experiências, mas vamos ver se eu consigo puxar pela memória. Mas, enquanto vou pensando, vou talvez focar um aspecto que foi vivenciado por mim como mulher negra, mas que foi praticado por uma outra pessoa negra. Mas o que eu reparo é que esse foi um tratamento pelo fato de eu ser negra... 
Crioula: E você poderia contar esse episódio?

Emmy Xyx: Isso foi depois da independência, não na minha infância. Na minha infância talvez eu já não tenha sentido tanto, pelo fato de, ou já me ter esquecido ou não ter dado conta, né?! Mas, por exemplo, o fato de eu estar a querer apanhar um taxi e achar que deva sentar no banco de trás e o motorista achar que eu deveria sentar à frente e abrir-me a porta da frente. Então, entendi aquilo como um fato, o fato de ele querer, insistentemente, que eu sentasse no banco da frente pelo fato de eu ser negra, porque não sendo, acho que ele não faria uma coisa dessas.

Crioula: E você se sentiu como? Você lembra dos sentimentos que teve?

Emmy Xyx: Bom, senti que essa pessoa achava que o fato de eu ser negra... É aquela coisa, somos negros e apesar de ele ser um motorista não é necessário que tu fiques atrás. Mais ou menos isso.

Crioula: E você tem lembrança de episódios discriminatórios pelo fato de você ser mulher? Lembrança de sexismo?

Emmy Xyx: As coisas estão sendo apresentadas agora assim sem muito tempo para fazer o rewind, de modo que está a ser um pouco difícil. Uma vez que eu penso que, com minha idade, eu vou apagar muitas coisas, e principalmente coisas que não agradam, eu faço questão de não as levar muito em consideração para a vida agora que eu estou a viver. Eu quero viver mais com coisas boas, lembrar coisas boas, acho que já vivi mais da metade do que vai ser a minha vida. De modo que 
eu não gosto muito de guardar, de lembrar, eu apago coisas que me incomodam. Eu faço o possível para por uma poeira e pronto. É por isso mesmo que, infelizmente, coisas assim que eu tenha me sentido mal e tal... é claro que estão lá, né?! Mas é preciso fazer uma grande limpeza, e eu neste momento prefiro... prefiro não... não estou a conseguir trazê-las. Se tivesse tido talvez uma preparação, eu haveria de fazer uma limpeza à mente e buscá-las.

\section{Crioula: E você se considera uma feminista?}

Emmy Xyx: Bom, eu não me considero feminista. O que eu tenho ouvido das pessoas em função daquilo que são as minhas reações em face de determinados temas que são abordados é que me dizem que sou feminista. Grande parte de homens diz isso, principalmente meus colegas da AEMO, da Associação dos Escritores Moçambicanos, dizem que eu sou feminista. Mas eu não me sinto como tal, se calhar sou e não sei o que é isso. O que eu acho é que as minhas posições são no sentido de achar que as mulheres...eu nem acho que o homem e a mulher sejam iguais, para mim são diferentes, são diferentes e têm maneiras de ser diferentes. $E$ eu até defendo que a mulher seja tratada com igualdade na sua diferença. $E$ a isso de se dizer que a mulher quer ser igual ao homem eu digo automaticamente que não, não quer ser igual ao homem, ela quer ser tratada com dignidade na sua diferença, mas com dignidade. Igual o modo como o homem deve ser tratado com dignidade de um homem é a dignidade de mulher. Eu acho que a mulher e o homem são metades que se complementam e tem que ser tratados de igual modo, mas na sua diferença. 
Crioula: Eu queria que você falasse um pouco agora sobre como começou sua relação com a literatura.

Emmy Xyx: Possivelmente, tenha começado com uns 12 anos. Eu me recordo que gostava de fazer versos e treiná-los. E eu então escrevia algumas coisinhas, que infelizmente nem guardei. Mas tentava rimar e gostava, sempre gostei de rima até agora. Mas depois a coisa morreu, não levei muito em consideração. Mais tarde, quando eu tinha por volta de 18 anos, faço o curso de Jornalismo e começo a escrever. Depois do curso, trabalhei no jornal Notícias como repórter estagiária e então eu tinha que escrever. Depois disso, tenho que deixar a profissão de repórter porque eu já havia casado e tinha filhos pequenos, e os horários do jornal não eram compatíveis com as minhas responsabilidades no lar e com as crianças, então acabei abandonando o ofício da escrita oficialmente. Então andei por outras ocupações que não estavam associadas diretamente à escrita. De qualquer modo, continuava a ler e, quando tive mais tempo e os meninos estavam um bocadinho mais crescidos, e sem o estresse do dia a dia, comecei a escrever de novo, e passei a ter uma coluna no jornal Embondeiro. Eu designei esta coluna de Kunyola-nyola, que significa escrevinhar, esgravatar a terra como as galinhas fazem, como falamos na língua Cinyungwe, que se fala em minha província de origem. Então eu todas as semanas tinha um artigo.

Crioula: Por que você deu o nome de Kunyola-nyola à sua coluna?

Emmy Xyx: Porque eu achava que, de fato, eu não estava a escrever. Estava a escrevinhar, a tentar escrever. Ainda não 
estava no nível daquilo que eu acho que é uma escrita. Então que as pessoas me desculpassem logo pelas falhas da minha escrita. Achei que era uma maneira de dizer que estava a escrever, mas com muita humildade. Eu até tinha entre parênteses o que o nome da coluna significava, justamente para que as pessoas não levassem muito a sério o que eu estava a escrever, e sobretudo a forma como eu estava a escrever, porque era uma iniciante na escrita, que tem a paixão pela escrita, mas reconhece suas limitações. Nesta coluna, coloquei meu endereço eletrônico, porém não recebia o retorno dos leitores. Em seguida o jornal fechou, e eu passei para o jornal Zambebe, que existe até hoje. $\mathrm{E}$, ao não ter uma reação por parte dos leitores, pensei que não valia a pena escrever. [...] só tive uma reação a um artigo em que eu abordava a homossexualidade, foi uma reação muito forte de um leitor que estava contra minhas ideias. Fora isso, e não tendo tido nenhuma reação, eu desisti de escrever. Passados cinco, seis ou dez anos depois, estou no convívio das crianças e é pedido aos pais para que se apresentassem, e eu apresento-me com meu pseudônimo da coluna. Eu disse "sou a titia Emmy Xyx", pois estávamos com crianças e todos os adultos eram tios. Então meu sobrinho depois me conta que um amigo dele lhe pergunta: "Aquela que é a Emmy Xyx?", e ele responde "Sim, é ela. Emmy Xyx é aquela que escrevia no jornal Embondeiro e depois foi para outro também". Em seguida, seu amigo diz "Afinal, é ela!?, perguntando todo admirado. Ele havia recortado todos aqueles textos dela, e disse que gostava muito dela e não sabia por que ela havia parado de escrever. 
Como minha casa estava muito perto, então meu sobrinho o traz aqui, chega em minha casa e eu fico muito admirada. Trocamos contato, ele me pediu um autógrafo, e disse que gostava de mim, que não imaginava que eu fosse como era, achava que eu era mais nova, que eu tinha uma outra raça...quer dizer, completamente diferente, mas que gostava de meus textos. E ele não imagina que aquilo para mim foi a melhor notícia que eu tive durante o tempo todo, afinal eu tinha pelo menos um fã, que até chegava a recortar os textos de minha coluna. Eu fiquei maravilhada, e foi ele quem me deu o impulso para continuar a escrever. E continuando a escrever, como tinha muita coisa para escrever, comecei a escrever naquela época. Porque essa coisa de escrever semanalmente é uma pressão, é preciso ter uma grande disciplina e tempo, e naquela altura eu estava a trabalhar e nem sempre tinha tempo. Havia decidido que faria uns cinco, seis textos, ficaria com um mês de avanço e iria escrevendo não com aquela pressão de "naquela semana tenho que escrever", porque teria de reserva alguns textos. Só que, quando comecei a escrever, nunca mais parava. $E$ foi assim que surgiu meu primeiro livro, o Espelho.

Crioula: Que lembranças você tem da província de Tete? Essas lembranças aparecem em sua escrita?

Emmy Xyx: Aparecem de certo modo. Minha província tem características muito específicas. É onde se registram as temperaturas mais altas e mais baixas. Eu nasci em Angônia, que é um distrito da província de Tete, e fiquei lá até os dois anos de idade. Depois, venho para Maputo, volto para Tete com cinco 
ou seis anos e em seguida começo a estudar. Fiz o ensino primário em Moatize [cidade da província], mas não havia o ensino secundário, era uma vila. Moatize ficava a vinte quilômetros da cidade de Tete, capital da província, e tínhamos que atravessar o rio Zambebe. Todos os dias precisávamos apanhar um ônibus até Tete e, como naquele tempo ainda não havia ponte, apanhávamos um daqueles barquinhos com capacidade para vinte pessoas em direção à outra margem, e depois íamos a pé até a escola. Minha escola era a Escola Técnica, que oferecia os cursos de comércio e indústria. $E$ eu ainda me recordo de todo o trajeto até a escola, de passar pelos embondeiros, todas aquelas árvores formosas. Era só olhar as árvores e já sabíamos onde estávamos, nem precisava ver mais nada. Era uma maravilha, víamos também maçaniqueiras, que produzem o maçanico, um fruto muito bom. Eu me lembro ainda que na escola nos mandavam colar nas paredes de casa um cartaz dizendo "do levantar ao deitar, português deves falar", pois não podíamos falar as línguas nacionais.

\section{Crioula: Era proibido?}

Emmy Xyx: Não era proibido, pois não me lembro de alguém ter recebido algum castigo pelo fato de ter falado [uma língua nacional], mas era um dever falar português. $E$ eu não me esqueço desse ditado nas paredes da sala de aula, e depois em casa também.

Crioula: Por que você quis começar a escrever?

Emmy Xyx: Eu penso que é um gosto. Da mesma maneira que as pessoas gostam de desenhar, de repente você pega 
uma caneta e começa a desenhar, pega um tecido qualquer e começa a costurar um vestidinho de uma boneca, de repente tu colocas uma música e põe-se a dançar. Então, de repente, eu me vejo escrevendo. Possivelmente, é um momento em que me sinto bem, que me sinto realizada.

Crioula: Mas você se lembra de onde veio esse gosto pela literatura?

Emmy Xyx: Eu não me recordo muito bem. De repente eu me via escrevendo. Vem da leitura de poemas, dos livros que nós tínhamos na escola, havia poemas, havia textos em prosa. Gostei da poesia, das rimas, daquela coisa de jogar com as palavras, com aquele som. Me encantava.

Crioula: Em alguns textos literários, você trata muito da questão da mulher. Por que? Que mulher é essa que aparece em seus textos?

Emmy Xyx: Eu falo sobre a mulher sim, e principalmente falo de maneira explícita em meu texto em prosa. E que mulher é essa? Essa mulher não é muito específica, eu falo principalmente da mulher que é mãe, da mulher que provavelmente seja encarada como culpada pelo fato de ser mãe, daquela que de certa forma é encoberta pela sociedade, para mim principalmente pelo fato de ser mãe. Penso que falo essencialmente de mulher mãe.

Crioula: E por que tratar dessa questão da mulher mãe? Emmy Xyx: Porque sou mulher e mãe, e acabo vivendo essa situação de mãe num mundo que parece estar contra a mater- 
nidade, cujas razões nos fazem sugerir que o fato de ser mãe - que para mim é algo sui generis - é um assunto tratado com uma certa gereza [prisão], e até às vezes com um sentido de culpa, de inferioridade, de uma coisa que parece menosprezada. A minha percepção em relação ao mundo e à sociedade no geral é a de que a mulher mãe - de que eu trato - não deveria existir, e que parece que precisamos arranjar outras mães, mães mais perfeitas. Entendo que a mecânica do mundo e de todo esse sistema está em volta disso, da maternidade. Todos temos um umbigo, não conheço ninguém que não tenha um umbigo, mas estamos à procura de um homem sem umbigo. Por todas essas discussões que existem, entendo que um homem perfeito talvez seja um homem sem umbigo...

Crioula: E como ficam as mulheres nessa situação? O que isso acarreta para as mulheres?

Emmy Xyx: Acarreta para as mulheres uma dupla responsabilidade, porque eu vejo que é como se fosse o jogo da culpa e da razão: a culpa procura a razão, a razão procura a culpa, a razão se sente culpada e a culpa tem razão. Sinto este tipo de jogo, em que se pretende dar culpa à razão e a culpa ser ilibada de culpa. A mulher nesta situação tem sobre si uma maior responsabilidade e uma dupla tarefa de perceber essas nuances que a vida lhe apresenta e saber gerir. E eu modestamente dou mérito a mulher pelo fato de ela se manter ainda nessa...estou a ser feminista [risos]...

Crioula: Mas você acha que é difícil para a mulher ser mulher e mãe nessa sociedade? Por que? 
Emmy Xyx: Sim. Estamos vivendo em uma sociedade machista. É uma sociedade que diz que a mulher não deve fazer isso, não deve fazer aquilo, que não deve estudar, que tem de ficar em casa tratando disso e daquilo...em relação à educação, a prioridade é para os homens, no emprego, a prioridade é para os homens, e por aí...estamos em uma sociedade machista. Isso tudo coloca as mulheres em um desafio, mas o mérito de tudo isso é que, de fato, a mulher percebe porque ainda estão sendo dados esses desafios, porque o próprio machismo é um sentimento de inferioridade, eu encaro o machismo como um sentimento de inferioridade em relação à mulher. E é esse sentimento de inferioridade que faz com que a sociedade considere por si só o homem como superior somente pelo fato de ser homem. É um mecanismo que a sociedade encontra para reduzir aquela superioridade que os homens pensam que as mulheres têm. Só pelo simples fato de saberem que se formaram dentro do ventre de uma mulher eles se sentem inferiores. Em última instância, a decisão está na mulher, e a vida forma-se na muIher. O machismo para mim é esse complexo de inferioridade que o homem tem perante a mulher.

Crioula: Não somente em seu livro de prosa, mas também em sua poesia, me parece que você também traz essa questão da condição da mulher na sociedade patriarcal. Por que essa tarefa de trazer isso para a literatura?

Emmy Xyx: Eu digo que para escrever e publicar é preciso ter coragem, pois nós dizemos o que há no nosso íntimo, o que há de mais profundo, eu pelo menos escrevo o que há de mais profundo em mim, o que há no meu eu, na minha essência. 
Está lá, está nos livros. A minha essência é essa essência feminina, de ser mulher, e eu não posso fugir disso. $E$ isso não é só na escrita...em qualquer ato, em qualquer atividade em que nós nos empenhemos, estamos nós lá, e essa é minha essência.

Crioula: E o que você espera de sua literatura? Especialmente dessa atenção que você colocou sobre a mulher. Qual sua pretensão quando você fala da mulher em sua literatura? Ao escrever você busca de alguma maneira alguma transformação social? Aponta algum caminho para essa transformação social pela escrita?

Emmy Xyx: Eu penso que sim. Através da escrita eu retrato aquilo que são as minhas leituras, minhas interpretações, minha compreensão em relação ao mundo, aquilo que é o porquê de nós agirmos desta maneira. Estava a explicar porque os homens oprimem as mulheres. Nós precisamos perceber, pois temos que saber onde nos situar. $E$ para saber onde se situar e como se comportar é preciso que a gente perceba o mundo, principalmente se queremos transformá-lo. Primeiro temos que perceber. Em relação à literatura, temos que ler, ler e ler. Lemos vários livros e vários autores, e não só a leitura pelos livros, como também de outras formas, e tentar perceber por que eu, nesse caso como mulher, sou tratada dessa forma, o que está por detrás disso, o que se pretende e, a partir daí, saber como me comportar. Este processo de transformação é muito longo, lento e é preciso perceber. Eu não tenho muitas ilusões, porque, cá para mim, penso que esta questão da opressão da mulher tem fundamentos na própria natureza da mulher, da forma como a mulher nasce, como o 
homem nasce. Percebendo isso, conseguimos perceber porque há este e aquele comportamento. Agora, mudanças radicais [só ocorrerão] se a natureza mudar. $E$ eu acho que é para isso que estamos a caminhar, estamos caminhando para mudanças climáticas e por aí.

Crioula: E como é essa diferença que você coloca como natural entre o homem e a mulher? Que natureza é essa da mulher? Emmy Xyx: A natureza da mulher é a maternidade. Essa é a natureza da mulher para mim.

Crioula: E isso coloca a mulher em qual lugar?

Emmy Xyx: A sociedade é que coloca a maternidade. Essa que é a grande questão: em que lugar se coloca a maternidade? Para mim a mulher resume-se na maternidade. Naturalmente.

\section{Crioula: Por que?}

Emmy Xyx: Penso que a maternidade é a essência do homem, do ser humano. A maternidade é o princípio da vida. Para mim, o resto é carnaval, é folclore. Questões fundamentais da sociedade, da economia e da política são o revestimento do átomo que é a maternidade. Mas se a mulher é o princípio, será que estamos diante de uma virgem maria? São todas essas questões em volta que se colocam pelo próprio homem, e o homem anda à procura de sua origem. Ou não. Estará o seu início nele mesmo ou em outro ser? E o que é a maternidade para o homem? Como eu vejo isso: todas essas questões se resumem nessa preocupação, nessa falta de respostas que satisfazem, pois nós podemos encontrar respostas para nossas perguntas, mas quando elas não nos satisfazem 
e quando partimos de determinados dogmas não vamos conseguir respostas...as que encontramos não nos satisfazem. $E$ se partimos para alguns preconceitos para encontrar as respostas, fingimos que estamos satisfeitos com elas, pois são essas respostas que nos convêm. Mas no fundo sabemos que não é isso. Tudo isso acaba criando essa sociedade que nós temos, essa sociedade que oprime a mulher.

Crioula: $E$ essas são questões que também reverberam em sua literatura?

Emmy Xyx: De certo modo, penso que sim. Em meu livro de prosa está muito mais explícito, já na poesia está de forma muito subjetiva.

Crioula: Todas essas perguntas?

Emmy Xyx: Todas essas perguntas estão lá [risos].

Crioula: Como escritora, o que você pretende alcançar com sua literatura?

Emmy Xyx: O que eu pretendo alcançar é partilhar com os leitores aquilo que são minhas percepções, o que eu acho que é o fundamento, a essência da vida. Agora estivemos a falar do papel da mulher e porquê desse machismo. É toda essa partilha daquilo que é a minha visão sobre o mundo. Eu posso estar preocupada sobre um determinado assunto, mas às vezes me sinto preocupada e não sei bem com o que, mas quando descubro o porquê da minha preocupação, tenho metade da preocupação resolvida. Então o que eu acho e par- 
tilho com leitores é essa minha compreensão em relação ao mundo, a esta questão em particular: por que a mulher é oprimida, por que é vista como a que não é capaz? Meu objetivo é esse mesmo de partilha, porque, depois dessa compreensão, é muito mais fácil viver e conviver. Digamos que estamos numa luta pela emancipação da mulher, pela igualdade...mas será que é de fato uma luta? E para mim não acaba sendo uma luta...

Crioula: E não sendo uma luta é o que?

Emmy Xyx: Eu não posso lutar por uma situação que é natural. Eu não vou lutar contra minha natureza, eu não vou lutar para minha transformação no sentido de transformação natural. Se eu nasci assim, por que não vou gostar de mim?

Crioula: Mas aí você está se referindo a uma condição de oprimida?

Emmy Xyx: Não. Repare que eu disse que a essência dessa questão de opressão da mulher é o fato de ela nascer mãe, é a maternidade que está na mulher. Então o homem vê na muIher um grande adversário, um bicho de sete cabeças. Pela natureza competitiva que o homem tem, ele acaba tentando se comparar com a mulher, e nessa comparação ele se sente inferior, na medida em que nasceu da mulher. Eu então percebendo toda essa opressão, toda essa questão no sentido de inferiorizá-la - e como eu disse é um disfarce que o homem coloca para não mostrar seu sentimento de inferioridade percebo por que há todo esse machismo à volta. $\mathrm{O}$ machismo acaba sendo uma fragilidade, uma fraqueza do homem. 
Crioula: Mas em relação à luta de emancipação da mulher, que não seria uma luta...

Emmy Xyx: Sim. Não é uma luta porque a mulher aos olhos do homem já é superior. Vais lutar o que se já é superior? Esta é uma ilusão...

Crioula: Mas é uma ilusão que temos no concreto com muitas mulheres oprimidas, discriminadas e vivendo preconceitos pelo simples fato de serem mulher...

Emmy Xyx: Sim...

Crioula: É uma ilusão com resultados concretos. E o que fazemos com isso?

Emmy Xyx: O que fazemos com isso, e é aquilo que faço pelo menos através de minha poesia é... Primeiro, é preciso que a mulher nunca se considere como o machismo pretende que a mulher se sinta. $E$ tem que perceber que aos olhos dos tais machistas - porque também a escolha do machismo não é de homens, há também mulheres machistas - ela não é aquilo que o machista diz que é, é precisamente o contrário.

Crioula: Mas você acha que essa percepção resolve a questão da mulher?

Emmy Xyx: É o princípio. Tu não podes lutar por uma coisa que não estás a ver. Como se você estivesse num quarto cheio de fumo [fumaça] e há um leão, tu tens que ver o leão 
para poder matá-lo, para poderes enfrentá-lo. Então é preciso que, sendo luta, primeiro temos que perceber...

Crioula: Mas se não é uma luta, você diria que é o que?

Emmy Xyx: Não é luta o que é preciso. Tendo considerado que ao fim e ao cabo é um processo de inferioridade do homem diante da mulher, o alvo a ser objeto de tratamento não é a mulher, é o homem.

Crioula: Isso mesmo se pensarmos nas mulheres no interior de Moçambique, por exemplo? Na condição como elas vivem? Exploradas pelas famílias, pelos pais e pelos maridos... Emmy Xyx: Exatamente. Para mim eu vejo que estamos a encaminhar muito mal aquilo que devem ser as soluções. As soluções para mim passam pela educação e formação do homem, porque é ele que age mal, então é ele que tem de receber a informação, porque ele age pois tem um conceito, um preconceito na cabeça, porque ele é o complexado na minha forma de ver. Então ele é que tem de ser objeto de tratamento.

Crioula: E o que essas mulheres podem fazer para sair dessa condição de exploradas e oprimidas? Falo isso pensando nas mulheres que vivem lá no interior...

Emmy Xyx: O foco, o objeto tem que ser naquele que age, não na vítima. 
Crioula: Mas como fazemos isso concretamente?

Emmy Xyx: As coisas não podem ser vistas de forma isolada. Aquilo que está sendo feito em relação à mulher na educação, nas oportunidades de emprego está muito certo, mas repare que não são somente as mulheres do campo ou as pessoas que não têm educação que sofrem. Certamente, não existem medidores de opressão, mas aqueles que têm uma situação financeira estável e um status também às vezes são muito mais oprimidas do que a mulher do campo. Por isso eu digo que, a par daquilo que é feito para as mulheres, o foco também tem que ser para os homens. Eles precisam sentir que são úteis para a sociedade, que o mundo não se resume na maternidade, e que essa maternidade também tem como um dos fatores essenciais a própria paternidade. Isso eles têm que perceber e, se eles não percebem, há de haver sempre opressão, complexo de inferioridade e medo de não ser útil, pois ao fim e ao cabo para mim não é nada menos que um não se sentir útil perante a sociedade. Então que tudo resume-se na maternidade e pronto, é isso. Por exemplo: existem situações de abortos e de crianças que são deitadas [enterradas] na vala comum e por aí afora. Em uma situação dessas, só olham para a mulher, a mulher que é castigada, que fez isso, aquilo...nós não sabemos o que teria dado origem para que a mulher fizesse esse tipo de situação, para ter tido esse tipo de conduta. Provavelmente, tenha sido o próprio pai da criança que tenha dito...quando a mãe diz não ter conseguido fazer o aborto e a criança nasce, mas o pai não quer, e vem a dizer "sou eu quem sou o pai, sou o responsável", cria-se uma situação tal que leva a um desespero que leve a tomar 
uma atitude dessas. Nós temos que partir do princípio que toda criança é bem-vinda...uma gravidez é uma graça, uma satisfação, uma realização da própria mulher. Então quando há uma situação contrária a essa, é preciso que se estude primeiro. O que teria levado... por que nessas situações a gente só se resume na mulher? Mas quando são coisas boas vamos para os homens? Penso que o problema principal para mim é exatamente esse: o homem deve ter a consciência de que ele também é útil para a sociedade.

Crioula: Sobre sua experiência como escritora contemporânea, é difícil fazer parte do universo literário sendo mulher e sendo negra?

Emmy Xyx: Não é fácil. Já vimos que a vida da mulher não é fácil, então a vida de uma mulher escritora não é uma exceção à regra, infelizmente. Eu tenho uma opinião diferente de algumas mulheres e de grande parte dos homens...penso que a mulher na literatura tem uma maneira muito específica e muito sua de se expressar. Penso particularmente que principalmente os verbos, a conjugação verbal, não usa sutiã... pelo menos na língua portuguesa, aquela que aprendi. É uma conjugação de homens, é um homem que está a conjugar um verbo. Por exemplo: eu falo, eu nado. Repare que tanto o falo quanto o nado são substantivos masculinos. Penso então que a mulher é colocada na $3^{a}$ pessoa na língua portuguesa: ela fala, ela nada. Eu digo isso pois trabalho com a palavra e gosto de rimar, e de certa maneira quando eu faço esse jogo de palavras sempre me coloco como homem ao me colocar na primeira pessoa, como autora. Então digo que os verbos de fato não usam sutiã, e essa para mim é uma dificuldade 
que tenho como escritora, pois a língua portuguesa em sua conjugação considera o homem como objeto da ação, como primeira pessoa, e eu fico embaraçada. Eu digo que a língua portuguesa é machista, a conjugação dos verbos é machista, é o homem que está a falar e ponto final.

Crioula: E na sua língua materna, aconteceria a mesma coisa? Emmy Xyx: Infelizmente, meu pai sempre quis que nós falássemos português, então eu tenho pouco domínio da minha língua materna, mas estou estudando, tenho até dicionário e quero escrever um livro bilíngue, que seja português e na minha língua materna, que é o nhúngue, e que seja traduzido para o português. Mas isso é teórico, eu vou escrever em português, e infelizmente vai ser assim. Tenho essa dificuldade de falar e não tenho o domínio de minha língua materna, então não sei como as coisas se colocam. Mas tenho esse projeto e penso que neste ano vou conseguir terminar. Tenho a impressão que a conjugação dos verbos não tem em feminino e masculino na minha língua, mas não posso garantir. Mas na língua portuguesa eu sinto isso, e é uma dificuldade para mim. Sobre esta questão de como me sinto na literatura como mulher, já tenho uma língua que me trai, e de me sentir assim já não fico muito à vontade, pois para escrever tu tens que gostar da língua e sentir-se bem com a língua, dominar a língua e virá-la de cabeça aos pés. Quando tu começas a ver que a própria língua não te coloca na primeira pessoa, tu já te sentes um pouco embaraçada. Então para mim pode parecer mesquinho, mas faz parte. É um golpe psicológico que está se dando. Então significa que tenho de me colocar no lugar do homem. Começando por isso, digo que a própria 
língua já não está a favor da mulher. Não é a mulher que tem a ação, as ações sempre são masculinas: eu falo, eu nado, eu canto...e ela canta, ela...A mulher tem sentimentos próprios e é coloca na língua sempre na voz passiva... mas, quando tu estás a escrever, estás sempre na voz ativa. Estás a escrever, a expressar, então essa é uma ginasta [um exercício] que eu acabo tendo que fazer por causa dessa questão de gêneros. Essa sociedade acaba nos obrigando a sermos todos homens e a não gostarmos da mulher. Eu tenho ouvido dizer "Ah, [a autora] escreveu tão bem, nem parece que é uma mulher", então já há o preconceito, aquele conceito de que mulher não escreve, que as mulheres escrevem lamúrias, que são choramingonas, que só falam de panelas, de galinhas no quintal. O machismo acha que as mulheres já são premiadas, então serem premiadas pela sociedade seria uma dupla premiação, então quem precisa ser premiado são os homens, pois as muIheres já são premiadas.

Crioula: E que premiação é essa?

Emmy Xyx: A maternidade. O machista entende que a mulher já está premiada pela maternidade que elas têm.

Crioula: Você se lembra de algum episódio em que você foi discriminada por ser mulher e por ser negra?

Emmy Xyx: Como escritora?

Crioula: Você quem escolhe. 
[Neste momento, a autora pensa em falar de um caso no qual foi vítima de discriminação, porém desiste para que as pessoas não fiquem sabendo, evitando assim uma situação "embaraçosa". Logo em seguida, começa a pensar em outra situação para contar].

Emmy Xyx: Já sofri [discriminação] por ser negra...há tantos, há tantos...em uns tempos que já se foram, se tu fosses para um restaurante poderiam passar umas pessoas e...

Crioula: Você se lembra de algum episódio que tenha acontecido com você nesse sentido?

Emmy Xyx: Sim, eu me lembro.

Crioula: Você se recorda que sentimentos teve? Emmy Xyx: De revolta.

Crioula: Algo em específico?

Emmy Xyx: Bom, não foi em Moçambique, foi na África do Sul. Nós queríamos viajar de Durban para Nelspruit em comboio [trem]. Havia várias classes e nós pedimos para viajar na segunda classe, era um bocadinho mais caro que a terceira classe. Na primeira classe disseram que já estava lotada e nem fizemos questão, mas preferíamos a segunda classe. Quando fomos comprar os bilhetes, disseram que já não havia mais para a segunda classe, e que só poderíamos comprar para a terceira classe. Compramos, mas a terceira classe estava muito cheia, então insistimos e fomos de novo à bilheteria e pedimos para comprar [bilhete para] a $2^{a}$ classe. Vimos 
que ela não estava cheia, mas não aceitaram e disseram que teríamos que entrar na $3^{a}$ classe e que, no meio do trajeto, poderiam nos passar para a $2^{a}$ classe. Não acreditamos, nem eu nem meu filho, e acabamos desistindo, pois estava impossível viajar do jeito que estava lotada a $3^{a}$ classe.

Crioula: E você sentiu que negaram a passagem pelo fato de você ser negra?

Emmy Xyx: Sim, eu senti isso.

Crioula: E para a publicação e circulação de um livro, você já sentiu discriminação por ser mulher ou negra?

Emmy Xyx: Por ser negra, não. Por ser mulher, também não. O que eu sinto são as apreciações, que até podem ser positivas, ou mesmo negativas. Positivas no sentido de dizer "Epa! Nem parece que é mulher"...não deixa de ser uma discriminação. Por acaso tenho mais apreciações deste gênero, mas não deixam de ser preconceituosas. Entendo que os homens são mais competitivos por natureza, então as competições para eles, os concursos literários estão à frente e a mim me parece que estão mais direcionados para os homens. Então eu acho - e tenho partilhado isso com alguns escritores, mas todos eles não concordam - que houvessem concursos literários femininos para motivar, para encorajar mulheres a escreverem. Num universo em que homens e mulheres estão a competir, pelo número de concorrentes masculinos a probabilidade que eles ganhem é maior. Então fazendo um concurso literário apenas com escritoras, naturalmente as mulheres participariam desse concurso menos desinibidas. Seria um 
concurso em que existiriam pessoas com a mesma experiência, que sofrem as mesmas opressões, e estariam mais à vontade. Essa é minha opinião. Entretanto, os homens dizem que não, que isto seria considerar que as mulheres seriam menos capazes, mas eu digo que não é isso. O que estou dizendo quando acho que poderíamos fazer um concurso só para as mulheres é para respeitar a mulher na sua diferença primeiro, e dar oportunidade para que elas possam livremente e sem outras comparações fazerem sua competição.

Crioula: E você acha que a literatura da mulher avançou no que diz respeito à valorização da mulher e da causa negra? A supervalorização do branco ainda é muito difundida no meio literário? Emmy Xyx: Eu penso que há agora um maior encorajamento para que as mulheres enveredem no mundo literário. Vemos mais mulheres, mas acho que acaba sendo um processo de desenvolvimento natural. $E$, por outro lado, havendo os tais concursos que sugiro, penso que iria encorajar muito mais. $\mathrm{O}$ que está a se dizer agora é que não precisamos estar aqui a se discriminar, muito bem, somos todos iguais, temos iguais oportunidades, muito bem. Não é bem assim... as coisas não podem ser vistas dessa maneira. Estamos diante de um pássaro cujas asas foram cortadas e outro pássaro que tem as asas inteirinhas. E não se vai por um pássaro com as asas cortadas, dizendo "agora pronto, já estamos todos iguais e vamos voar" e ver quem voa. Temos que ter consciência que fomos nós que cortamos as asas desse pássaro, então temos que fazer essas asas crescerem. O fato de todos estarem sempre a dizer "você não é capaz" acaba não sendo 
capaz mesmo, acaba criando esse complexo de que não sou capaz. Não é agora que, de um momento para outro, eu digo "pronto, já estamos todos capazes e somos todos iguais". Não é verdade. A mulher continua ainda - nem que seja só psicologicamente - com sua autoestima baixa e precisa de um tempo para refazer-se de toda essa opressão que sofreu durante milhares e milhares de anos. Então não é simplesmente pelo fato de dizer "agora é a emancipação da mulher e...". As coisas estão sendo vistas assim, o que não deve ser. [A literatura de mulheres] está avançando porque já não há aquela missa que ouvimos todos os dias de que a mulher não é capaz. Sabemos que agora há movimentos muito fortes que clamam por um tratamento igual à mulher em relação ao homem, mesmo no mundo literário. Mas temos que perceber que a mulher - apesar de abertamente, publicamente e perante a lei - está tendo mais oportunidades, ela própria está ainda numa situação de certa fragilidade decorrente de toda a opressão que recebeu, e por isso precisa de estímulos. Eu falo dos concursos literários como uma maneira de fazer as asas crescerem mais rapidamente.

Crioula: E em relação à supervalorização do branco no meio literário?

Emmy Xyx: Eu não vejo assim, penso que as coisas agora estão a mudar. Pelo menos eu não sinto isso.

Submissão: 13/05/2017

Aceite: 13/06/2017 